Egypt. Acad. J. Biolog. Sci., 4(1): 63-85 (2012)

Email: egyptianacademic@yahoo.com

Received: 19/6/2012
C. Physiology \& Molecular Biology

ISSN: 2090-0767

www.eajbs.eg.net

\title{
Synergistic Effect of Milk Thistle and Grape Seed Extracts on the Recovery of Fumonisin b1 Toxicity in Rats.
}

\author{
El-Shafeey $\mathrm{M}^{1,{ }^{*}}$; El-Adawi $\mathrm{H}^{1}$; Al-Azhari D. $^{2}$; Abd El-Wahab $\mathrm{A}^{1}$ and \\ Abdel-Mohsen $\mathbf{M}^{3}$
}

1- Medical Biotechnology Dept., GEBRI institute, City of Scientific Research and Technology Applications, New Borg El-Arab City, Alexandria, Egypt

2- Zoology Dept., Faculty of Science, Minia University, Minia, Egypt

3- Applied Medical Chemistry Dept., Medical Research Institute, Alexandria, Egypt

* (e.mail: mohamedshafeey@gmail.com)

\section{ABSTRACT}

Fumonisin B1 (FB1) is a mold metabolite produced by Fusarium species that is frequently found in corn worldwide. It is toxic to both liver and kidney. Hepatotoxicity was induced in rats by feeding them FB1 contaminated corn. Evidence of hepatotoxicity was observed after 60 days by an increase in the plasma activity of alanine aminotransferase (ALT), where that elevation reached $78 \%(\mathrm{p}=0.000)$, in comparison with the control group. Treatment with milk thistle $(\mathrm{S})$, or grape seeds $(\mathrm{G})$ extracts or both $(\mathrm{S}+\mathrm{G})$ was found to return the ALT level back to normal. FB1, drastically depleted glutathione peroxidase (GpX) to 48\%, while treatment with S,G, and $\mathrm{S}+\mathrm{G}$ could elevate the $\mathrm{GpX}$ by $76 \%, 76 \%$ and $35 \%$ respectively. Lipid peroxidation represented by malondialdehyde was elevated significantly to $137 \%$. On the other hand, the treated groups $(\mathrm{S}, \mathrm{G}$, and $\mathrm{S}+\mathrm{G})$ have altered the levels down to $47 \%, 42 \%$, and $29 \%$ respectively. In addition to the hepatotoxicity of FB1, the kidney function was investigated too, where the creatinine level was elevated to $65 \%$. The treatment by $\mathrm{S}, \mathrm{G}$ and $\mathrm{S}+\mathrm{G}$ lowered the level down to $16 \%, 15 \%$ and $2 \%$. Serum activity of urea was significantly elevated to $30 \%$, the treated group $\mathrm{G}$ could significantly reduce it to $23 \%$ while the treated groups $\mathrm{S}$ and $\mathrm{S}+\mathrm{G}$ could not reduce that elevation in urea level. Histological examination of liver sections confirmed the serum analysis, where significant improvements were observed in all treated groups in comparison with the liver sections of rats fed on FB1. These improvements might be due to their ability to lower serum total cholesterol and low- density lipoprotein cholesterol levels as well as slowing the lipid peroxidation process by enhancing antioxidant enzyme activity.

Keywords: Milk Thistle - Grape Seed Extracts- Toxicity - Rats

\section{INTRODUCTION}

Fumonisins are recently discovered mycotoxins in 1988, their chemical structure and biological activity were elucidated in South Africa (Gelderblom et al., 1988; Marasas, 2001). Fumonisin $\mathrm{B} 1$ is a mycotoxin produced by the fungus Fusarium verticillioides, is known to be the causative agent of several diseases in animals (Marasas, 1996), it causes equine leukoencephalomalacia (ELEM) (Marasas, 2001) and porcine pulmonary edema (Haschek et al., 2001; Marasas, 2001). Consumption of food containing $F$. verticillioides and/or fumonisins has been linked epidemiologically to the high incidence of cancer (Sydenham et al., 1991; Rheeder et al., 1992). Fumonisin B1 has the ability to alter sphingolipid metabolism by inhibiting the enzyme ceramide synthase, an enzyme responsible for the acylation of sphinganine and sphingosine. Structurally, fumonisin resembles sphinganine and sphingosine, free 
sphingoid bases that play critical roles in cell communication and signal transduction (Wang et al., 1996; Desai et al., 2002). The disruption of the sphingolipid biosynthetic pathway leads to increased levels of sphingolipid precursors and decreased levels of complex sphingolipids, since fumonisins disrupt sphingolipid biosynthesis, the resulting elevation in the sphinganine/sphingosine ratio in serum, plasma, or urine has been used as a biomarker for estimating dietary exposure to fumonisins in animals (Shephard et al., 1996a, b; Shephard and van der Westhuizen, 1998; Marasas, 2001).

Silymarin, an extract from seeds and fruits of milk thistle (Silybum marianum), is a mixture of flavonoid isomers such as silibinin, isosilibinin, silidianin, and silichristin. The seeds of this plant have been used in Europe for many centuries for the treatment of liver and gall bladder dysfunctions (Schulz et al., 2004; Wichtl, 2004; Blumenthal, 2003). Silymarin has liver regenerative effects by stimulating the enzyme known as RNA polymerase in the nucleus of liver cells. This result in increase of ribosomal protein synthesis helps to regenerate hepatocytes (Gruenwald, 2004). The ability of silymarin to protect against oxidative stress-induced hepatocellular damage (such as lipid peroxidation of membranes and subsequent membrane degradation) is associated with its free radical scavenging properties and its ability to enhance endogenous antioxidant defences, such as those mediated by SOD or the glutathione system (Schuppan et al., 1999; Pascual et al., 1993)

Grape (Vitis vinifera) is one of the most widely consumed fruits in the world. Grape is known as the "queen of fruits" because of cleansing properties. A "grape cure" or grape fast involves eating 3-6 pounds of grapes to detoxify and improve liver function (Grieve, 1971;
Bown, 2001). Additionally, it has been reported that grape has important role in controlling of some liver diseases, high blood pressure and anemia. Also fibers and fruit acids in grape have vital role in cleaning blood functions of digestive system and kidney (Celik et al., 1998)

Grape Seed Extract (GSE) is a medical herb used primarily for its high proanthocyanidin content. GSE is a naturally occurring plant substance that contains a concentrated source of antioxidant nutrients known as oligomeric proanthocyanidins (OPCs), which are more powerful antioxidants than vitamins $\mathrm{C}, \mathrm{E}$ and beta-carotene. GSE has been found to be the richest source of (OPCs).

\section{MATERIALS AND METHODS}

Chemicals: All chemicals were purchased from Sigma-Aldrich Co., Germany. ALT, Albumin, Total protein, Uric acid, Urea, Lipid peroxide and GPx Kits were purchased from Bio-Diagnostic Co., Cairo-Egypt, creatinine and lipid profile kits were purchased from Diamond Co., Cairo-Egypt.

\section{Animals and experimental design}

Fifty male Sprague Dawley rats average weight (100-120g) were used. Animals were caged in groups of five and given water ad libitum. After one week of acclimatization, animals were divided into two main groups. Group 1 of 10 rats were used as control (C-gp), where they were fed on uncontaminated corn; the second group of 40 rats served as the treated group where they were fed on contaminated corn with at least $250 \mathrm{mg} / \mathrm{kg}$ FB1 for 60 days. After that this group was divided into four groups: The first group (FB1-gp) of 10 rats served as positive control, the second one (Sp-gp) of 10 rats were fed on milk thistle extract (S-750 mg/kg b.wt.), the third one (G-gp) of 10 rats were fed on grape seed extract (G- 3g/kg b.wt.) and the fourth one $(\mathrm{G}+\mathrm{S}$-gp) of 10 rats were fed on mix of both extracts. At the end of 
experimental period, the animals were sacrificed. Blood samples were collected from animals in clean sterilized test tubes and serum samples were separated and used for analysis parameters.

\section{Extraction of GSE and Silymarin Pre-extraction sample preparation}

Red grape (Vitis vinifera) seeds were obtained from Ganaclise Veinyard factory (Abu-Elmatameer). Grape seeds were handily separated from grape skin and stem (waste), then washed with tap water and then left to dry in open air away from direct sunlight. Seeds were crushed in a coffee grinder for two min, but at $15 \mathrm{~s}$ on \& off intervals to avoid heating of the sample. The crushed seeds were wrapped and stored at $-18^{\circ} \mathrm{C}$ until the extractions were performed (Palma et al., 1999)

Milk thistle:

(Silybum marianum) seeds were obtained from a local market at Alexandria, Egypt. The seeds were handily separated from waste, then were washed with water, dried in open air and crushed in a coffee grinder as explained previously.

\section{Extraction process:}

The crushed samples (Grape and Milk thistle) seeds were subjected to preliminary treatment (defatting); crushed seeds were soaked in suitable volume of hexane overnight. Defatted seeds were extracted by pressurized hot water and lyophilized using lyophilizer (Telstar, Spain).

\section{Determination of phenol content}

The classic technique employed in phenol analysis is the 4-aminoantipyrine colorimetric procedure (Dannis 1951; Ettinger et al., 1951). The absorbance of the samples was read against blank at $500 \mathrm{~nm}$ using spectrophotometer (PerkinElmer Lambda EZ 201, USA). The concentration of the sample was calculated from the standard curve prepared previously.

\section{Determination of antioxidant activity}

The antioxidant activities of the herbs water extracts were determined using the ferric thiocyanate (FTC) method (Osawa and Namiki, 1981) with slight modification. The absorbance at $500 \mathrm{~nm}$ of the resulting red solution was measured, and it was measured again every $24 \mathrm{~h}$ until the time when the absorbance of the control reached the maximum value. The percent inhibition of linoleic acid peroxidation was calculated as:

$(\%)$ inhibition $=100-$
[(absorbance increase of the
sample/absorbance increase of the
control $) \times 100]$.

All tests were run in duplicate, and analyses of all samples were run in triplicate and averaged.

\section{HPLC analysis:}

The analysis for milk thistle seed extract was done using a Beckman-C18 column $(100 \times 4.6 \mathrm{~mm}, 5 \mu \mathrm{m}$ particle size), equipped with an autosampler, pump and UV/visible multi wavelength detector

\section{Serum analysis}

Blood samples for liver function, kidney function and lipid profile assays were centrifuged at $3000 \mathrm{rpm}$ for $15 \mathrm{~min}$. using centrifuge (Heraeus, Germany), and the resultant serum samples were stored at $-20{ }^{\circ} \mathrm{C}$ till analysis (Oser, 1965). Preparation of crude liver homogenate

Liver tissue homogenate was prepared for total glutathione peroxidase (GPx) determination according to Paglia and Valentine (1967). The protein concentration of the clarified homogenate was calculated to determine the required volume which should be added on this assay.

\section{Measurement of liver function markers}

Total proteins were determined by means of the biuret reaction as described by Gornall et al., (1949). In the presence of an alkaline cupric sulfate, the protein produces a violet color, the intensity of which is proportional to their 
concentration. Albumin was assayed according to the method of Doumas et al., (1971) where, a green complex of albumin/bromcresol was formed at $\mathrm{pH}$ 4.1 and measured spectrophotometerically at $630 \mathrm{~nm}$. Alanine aminotanseferase was determined following the method of Reitman and Frankel (1957). The catalytic activity was measured by spectrophotometery at $505 \mathrm{~nm}$.

\section{Measurement of kidney function markers}

Creatinine level was determined by colorimetric kinetic method as described by Bartels et al., (1972) and Larsen (1972), where Creatinine in alkaline solution reacts with picric acid to form a colored complex. Urea in the serum originated, by means of the coupled reactions described by Fawcett and Soctt (1960). The blue dye indophenol product reaction absorbs light between $530 \mathrm{~nm}$ and $560 \mathrm{~nm}$ proportional to initial urea concentration. Uric acid level was determined as described by Barham and Trinder (1972), where the uric acid was hydrolyzed enzymatically to release hydrogen peroxide which reacts with 4aminoantipyrine in the presence of 3,5 , Dichloro-2- hydroxybenzensulphonate to form a quinoneimine.

\section{Lipid profile}

The cholesterol was determined after enzymatic hydrolysis and oxidation according to Richmond, (1973) and Allain et al., (1974). The quinoneimine is formed from hydrogen peroxide and 4aminoantipyrine in the presence of phenol and peroxidase. The HDLcholesterol was determined by enzymatic colorimetric method as described by Burstein et al., (1970) and Lopez-Virella et al., (1977) where phosphotungstic acid and magnesium ions selectively precipitating all lipoproteins except the HDL fraction - cholesterol present in the supernatant can be determined by the same method used for total cholesterol. LDL-cholesterol was computed mathematically according to Friedwald's equation (Friedwald, 1972): LDL $=$ TC(HDL+TG/5)

\section{Measurement of malondialdehyde (MDA) and glutathione peroxidase (GPx)}

Malondialdehyde level was determined by the method described by Ohkawa (1979). Thiobarbituric acid (TBA) reacts with malondialdehyde (MDA) in acidic medium at temperature of $95^{\circ} \mathrm{C}$ for $30 \mathrm{~min}$. to form thiobarbituric acid reactive product, the absorbance of the resultant pink product can be measured at $534 \mathrm{~nm}$. The assay is an indirect measure of the activity of cGPx. Oxidized glutathione (GSSG), produced upon reduction of organic peroxide by c-GPx, and is recycled to its reduced state by the enzyme reductase (GR).

\section{Histological examination}

Liver specimens of each group were sliced and immediately fixed in $10 \%$ formalin. A rotator microtome was used to cut tissue into $4 \mu \mathrm{m}$ thick sections and mounting was carried out on clean glass slides. Finally, staining with conventional hematoxyline and eosin (H\&E) stain for examination of any histopathological changes was carried out Statistical analysis The data was given as individual values and as mean \pm standard error. Comparisons between the means of various treatment groups were analyzed using one way ANOVA. Differences were considered significant at $\mathrm{P}<0.05$. All statistical analyses were performed using the statistical software SPSS, version 10 .

\section{RESULTS \\ Antioxidant activity}

Fig. (1) and (2) show the inhibition of linoleic peroxidation by Silymarin and GSE respectively in comparison with ascorbic acid as a standard. From fig.(1), it was evident that the silymarin water extract could inhibit the peroxidation of 
linoleic more than ascorbic acid same effect of ascorbic acid on the especially in the third and fourth days.

On the other hand, from Fig. (2) the grape seed extract almost has the

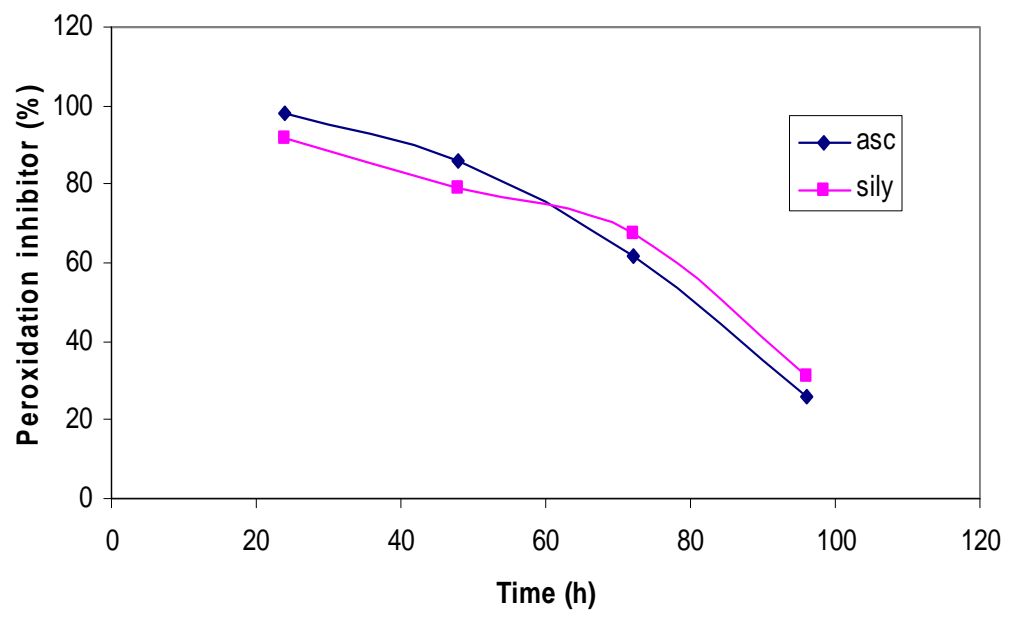

Fig. 1: Inhibition of linoleic peroxidation by ascorbic acid as a standard and silymarin as measured by the FTC method. Absorbance values represent means of triplicates of different samples analyzed.

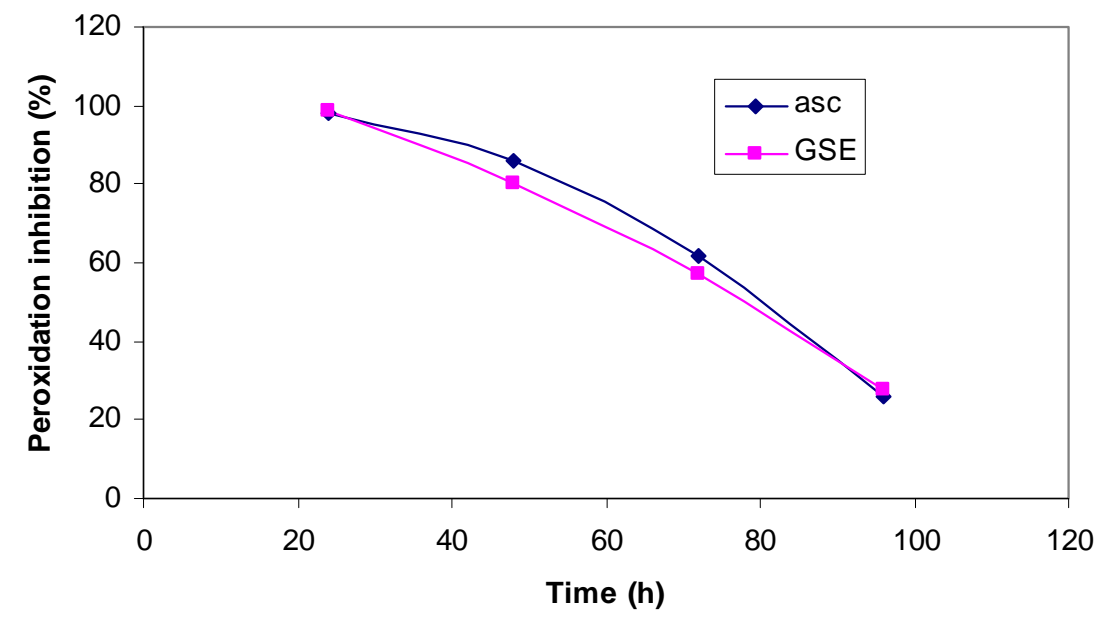

Fig. 2: Inhibition of linoleic peroxidation by ascorbic acid as a standard and GSE as measured by the FTC method. Absorbance values represent means of triplicates of different samples analyzed.

\section{HPLC Results}

1.1. Resulting chromatogram and gradient elution schedule for HPLC-UV analysis of Silymarin Extract

From the resulting chromatogram that is shown in Fig (3), the main compound in this extract was taxifolin and its derivative, the silybinin $\mathrm{A}$ and silybinin B were present in significant amounts. These compounds were identified by their retention times against standard samples. 


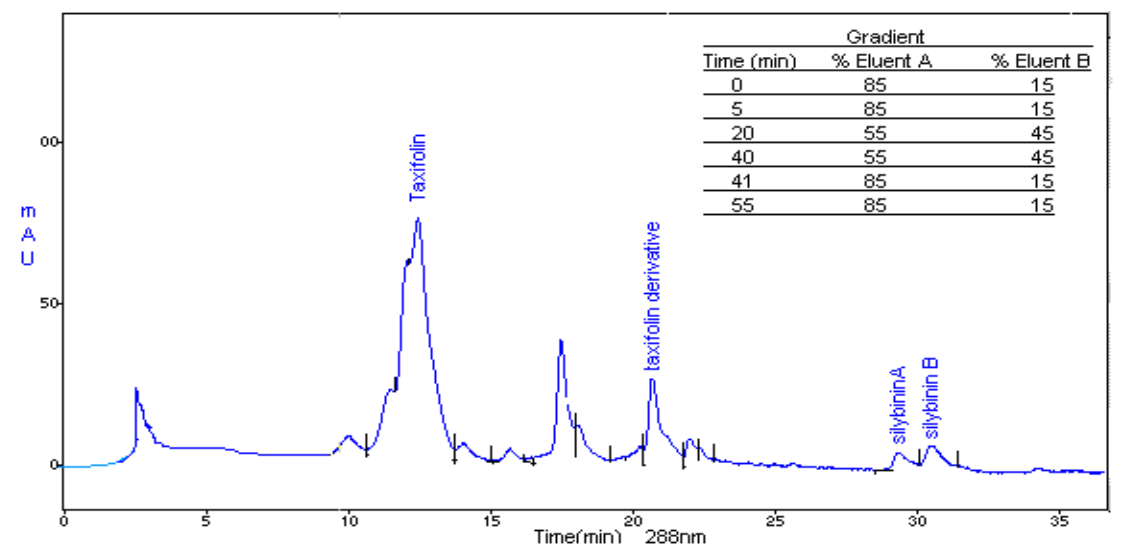

Fig. 3: Resulting chromatogram for HPLC-UV analysis of Silymarin Extract.

1.2. Resulting chromatogram and gradient elution schedule for HPLC-UV analysis of Grape Seed Extract

HPLC-UV analysis: Due to the high polarity of compounds presences in the extract, it was analyzed by HPLC-UV and the resulting chromatogram is shown in Fig. (4). The two main compounds in this extract were gallic acid and epicatechin. Catechin is also present in a significant amount, as well. These compounds were identified by their retention times against standard samples.

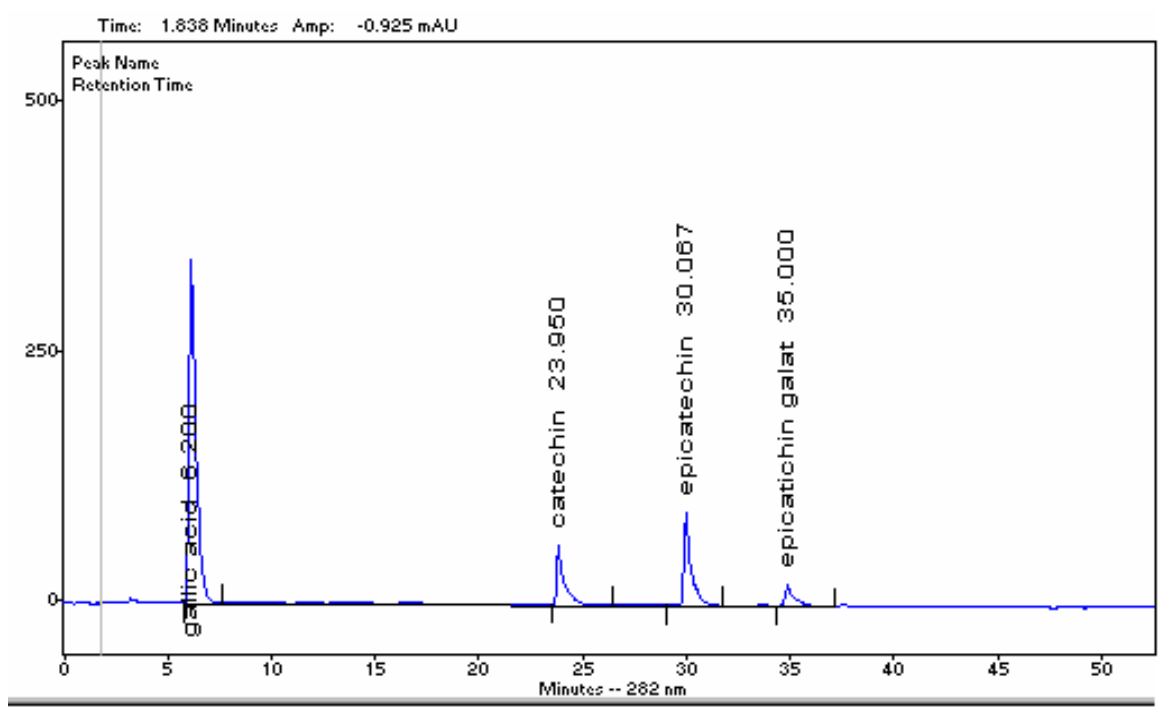

Fig. 4: Resulting chromatogram for HPLC-UV analysis of Grape Seed Extract.

\section{Biochemical Results}

\subsection{Treated results}

\subsubsection{Serum levels of alanine} aminotransferase (ALT)

The treated group (FB1-gp) on which the rats fed on fumonisin B1 contaminated corn, has recorded a very significant elevation in the mean serum activity level of alanine aminotransferase (ALT), that elevation reached to $78 \%$ ( $p$ $=0.000)$, in comparison with control group (C-gp). S-gp and G-gp could significantly lower the mean serum activity level of ALT by $25 \%(p=$ $0.001)$, and $26.7 \% \quad(\mathrm{p}=0.000)$, respectively in respect to that of FB1-gp, but significantly higher than that of C-gp by $33 \%(p=0.016)$, and $30 \%,(p=$ $0.022)$ respectively. In case of $\mathrm{S}+\mathrm{G}-\mathrm{gp}$ where the rats fed diet supplemented with both silymarin and grape seed extracts, they could return back the mean serum 
activity level of ALT to control level that it was significantly lower than that of FB1-gp by $32 \%(p=0.000)$, (Fig.5).

\subsubsection{Serum levels of total protein}

There was no significant change in the mean serum level of total protein in the FB1-gp, when compared to that of C$\mathrm{gp},(p>0.05)$. In the S-gp, there was no significant difference in the mean serum level of total protein when compared to that of C-gp or FB1-gp, $(p>0.05)$. The G-gp has been recorded a significant elevation in the mean serum level of total protein by $27 \%(p=0.000), 15 \%(p=$ $0.006)$ and $22.8 \%(p=0.000)$ when compared to that of C-gp, FB1-gp and S$\mathrm{gp}$, respectively. In case of $\mathrm{S}+\mathrm{G}-\mathrm{gp}$, the mean serum level of total protein significantly increased by $14 \%(p=$
0.014) when compared to that of C-gp, (Fig. 5).

\subsubsection{Serum levels of Albumin}

There was no significant difference in the mean serum level of albumin in the (FB1-gp) in comparison with that of Cgp $(p>0.05)$. G-gp showed a significant increase in the mean serum level of albumin by $16 \%(p=0.048)$ and $25 \%(p$ $=0.005)$ in respect to that of C-gp and FB1-gp respectively. The S-gp showed a significant increase in the mean serum level of albumin by $16 \%(p=0.028)$ when compared to that of FB1-gp. On the other hand, the S+G-gp showed a significant reduction in the mean serum level of albumin by $23 \%(p=0.001), 16 \%(p=$ $0.011), 28 \%(p=0.001)$, and $33 \%(p=$ $0.000)$ in comparison with C-gp, FB1-gp, S-gp, and G-gp, respectively, (Fig. 5).

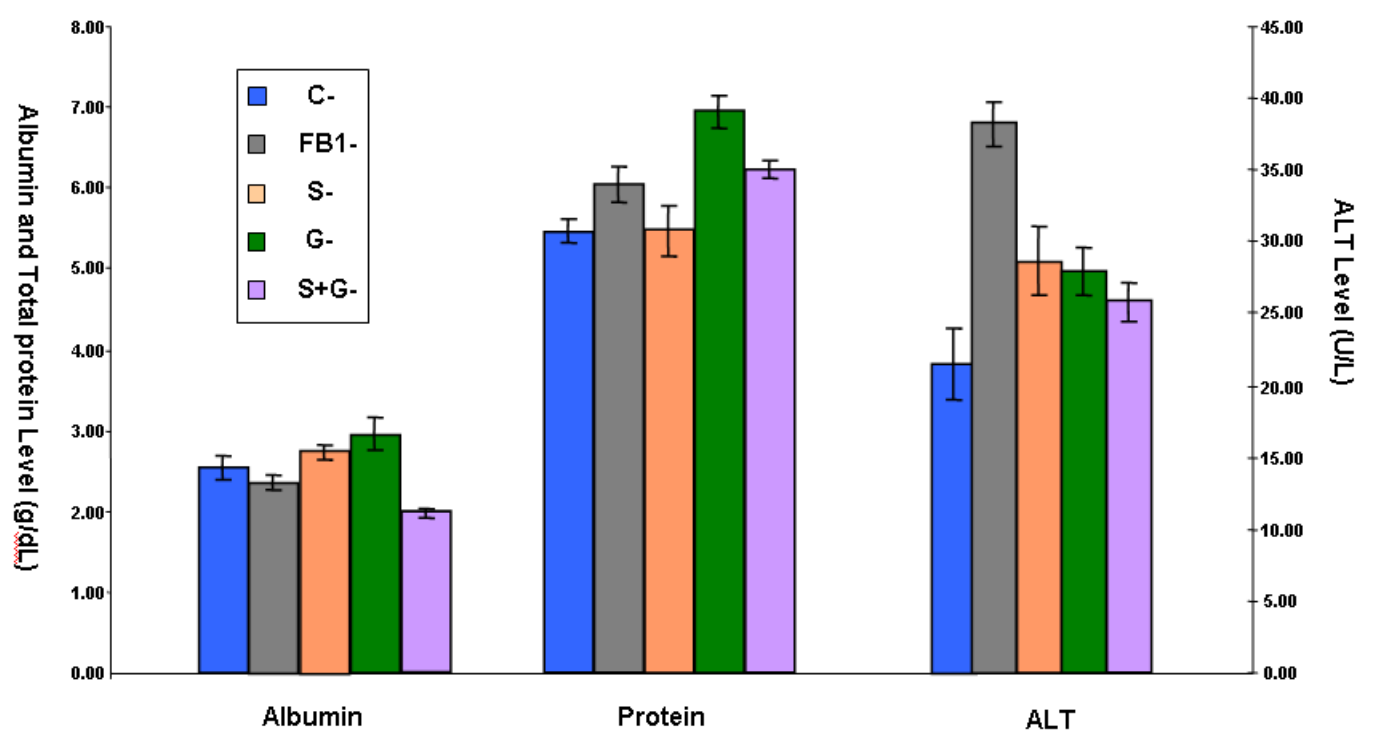

Figure (5): Serum Activity Levels of ALT, Albumin, and Total Protein in Treated groups

\subsubsection{Serum Total Cholesterol (TC) level}

The FB1-gp has recorded a significant increase in the mean serum level of total cholesterol (TC) by $51 \%(p=$ $0.000)$ when compared to that of C-gp. The treatment of rats with $\mathrm{S}$ after FB1 significantly decreased the mean serum level of TC by $32.6 \%(p=0.000)$ in respect to that of FB1-gp that it returned back to the normal level. The administration of G after FB1 in the G-gp significantly decreased the mean serum level of total cholesterol by $27.5 \%(p=$ 0.000 ) when compared to that of FB1-gp and showed no significant difference when compared to that of S-gp $(p>0.05)$. On the other hand the mean serum level of TC of the group of rats that fed on both $\mathrm{S}+\mathrm{G}$ after FB1 administration significantly lower than that of C-gp, FB1-gp, S-gp, and G-gp by $23 \%(p=0.000), 49 \%(p=0.000)$, $24.5 \%(p=0.000)$, and $30 \%(p=0.000)$ respectively, (Fig. 6). 
Figure (6): Serum Activity Levels of TC, HDL,TG and LDL in Treated Groups

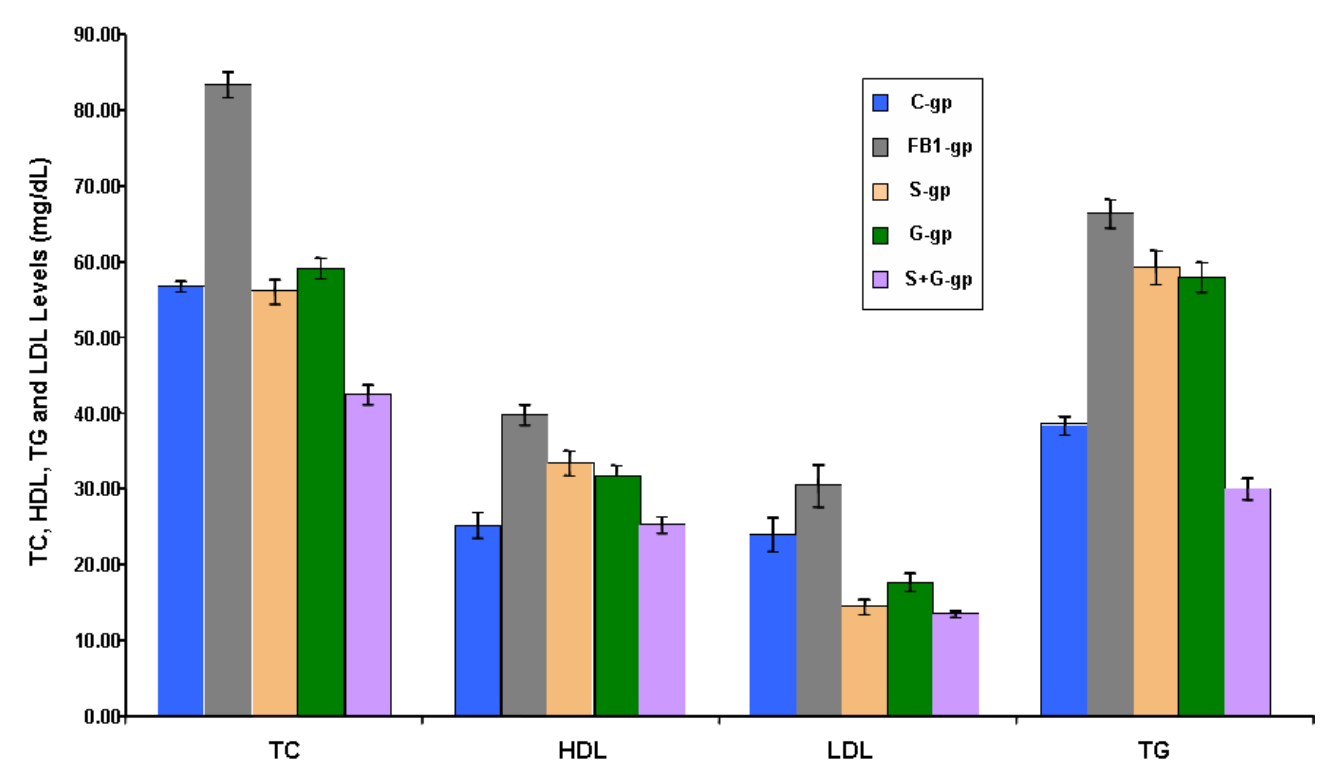

\subsubsection{Serum \\ Lipoprotein Cholesterol (HDL-C) level}

Feeding the rats with FB1 contaminated corn significantly increased the mean serum level of HDL-C in the FB1-gp by $58 \%(p=0.000)$ when compared to that of C-gp. The treatment of rats after FB1 with $\mathrm{S}$ significantly decreased the mean serum level of HDLC by $16 \%(p=0.003)$ when compared to that of FB1-gp. The mean serum level of the G-gp significantly reduced by $20 \%$ ( $p$ $=0.000)$ when compared to that of FB1$\mathrm{gp}$, but still higher than that of C-gp by $25 \%(p=0.000)$. The $\mathrm{S}+\mathrm{G}-\mathrm{gp}$ could return back the mean serum level of HDL-C to normal level when compared to that of C-gp, on other words could significantly decrease the mean level of HDL-C by $36 \%(p=0.000$ in respect to that of FB1-gp, (Fig. 6).

\subsubsection{Serum Low Density Lipoprotein- Cholesterol (LDL-C) level}

A significant increase in the mean serum level of LDL-C was observed in the FB1-gp, this elevation reached to $27 \%(p=0.019)$ in comparison with that of C-gp. The S-gp has been recorded a significant decrease in the mean serum level of LDL-C by $40 \%(p=0.001)$ and
$52 \%(p=0.000)$ in respect to that of C-gp and FB1-gp. The G-gp has been recorded a significant reduction in the mean serum level of LDL-C by $25 \%(p=0.027)$ and $42 \%(p=0.000)$ when compared to that of C-gp and FB1-gp. The S+G-gp have been recorded a significant reduction in the mean serum level of LDL-C by $43 \%$ $(p=0.001)$ and $55 \%(p=0.000)$, when compared to that of C-gp and FB1-gp, but showed no significant difference when compared to that of the other groups ( $p>0.05)$, (Fig. 6).

\subsubsection{Serum Triglycerides (TG) level}

The FB1-gp have been recorded a very significant elevation in the mean serum level of triglycerides (TG) by 72 $\%(p=0.000)$ when compared to that of C-gp. The treated groups S-gp and G-gp recorded a significant decrease in the mean serum level of TG by $10 \%(p=$ $0.009)$ and $12 \%(p=0.002)$ respectively in comparison with that of FB1-gp, but showed a significant increase in the mean serum level of TG by $54 \%(p=0.000)$ and $50 \%(p=0.000)$ respectively when compared to that of C-gp. The S+G-gp have been recorded a significant reduction in the mean level of TG by $21 \%(p=0.003), 54 \%(p=0.000), 49 \%$ $(p=0.000)$, and $48 \%(p=0.000)$ when 
compared to that of C-gp, FB1-gp, S-gp, and G-gp, respectively, (Fig. 6).

\subsubsection{Serum Creatinine level}

A significant increase in the mean serum level of creatinine was observed in the FB1-gp by $65 \%(p=0.000)$ when compared to that of C-gp. The mean serum level of creatinine in S-gp and in G-gp recorded a significant reduction by $16 \%$ and $15 \%$ when compared to that of
FB1-gp but recorded a significant increase by $38 \%(p=0.000)$ and $39 \%(p$ $=0.000)$ respectively when compared to that of C-gp. The S+G-gp showed a significant reduction by $22 \%$ in the mean serum level of creatinine in respect to that of FB1-gp $(p=0.000)$ but recorded a significant increase by $28 \%$ in comparison with that of C-gp (Fig. 7).

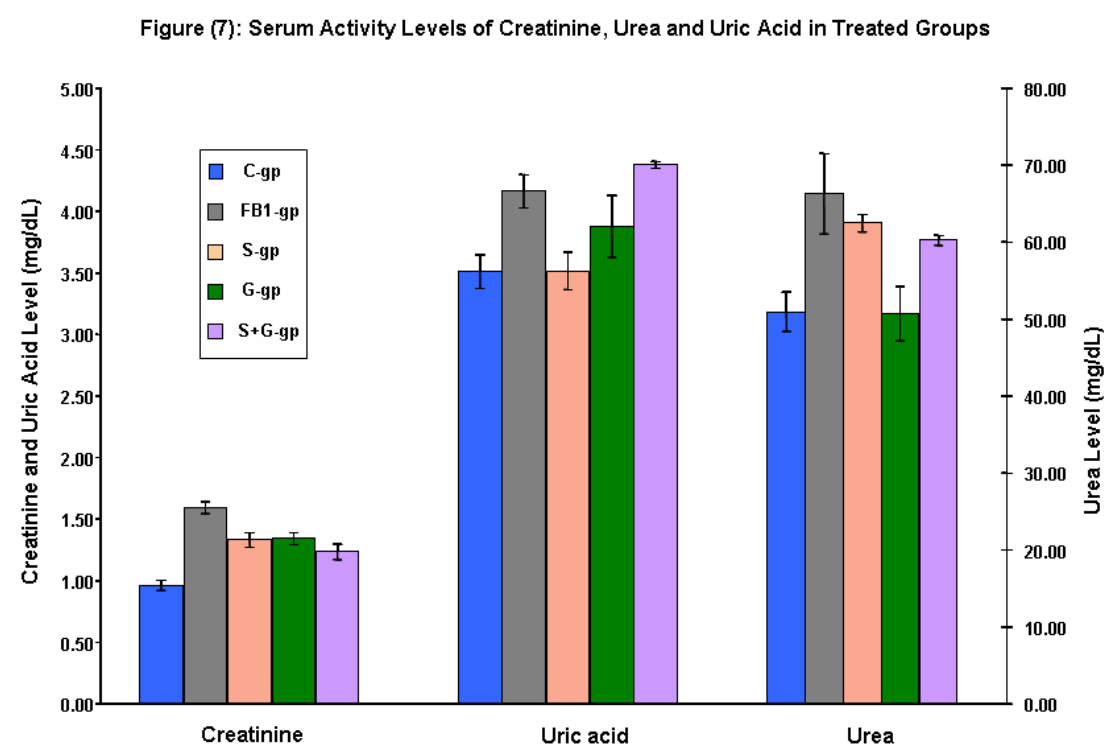

\subsubsection{Serum Uric Acid level}

The FB1-gp in which the rats fed on FB1 contaminated corn showed a significant increase in the mean serum level of uric acid by $18 \% \quad(p=0.006)$ when compared to that of C-gp. The S-gp showed a significant decrease in the mean serum level of uric acid by $15 \%$ $(p=0.006)$ in respect to that of FB1-gp. No significant difference in the mean serum level of uric acid of the groups of rats that fed on $\mathrm{S}$ and $\mathrm{G}$ separately after FB1 administration when compared to that of C-gp $(p>0.05)$. On the other hand the group of rats that fed on both $\mathrm{S}+\mathrm{G}$ after $\mathrm{FB} 1$ administration significantly increased the mean serum level of uric acid by $24 \%(p=0.001)$, $24 \%(p=0.001)$, and 13\% $(p=0.034)$ when compared to that of C-gp, S-gp, and G-gp respectively. No significant difference in the mean level of uric acid in the $\mathrm{S}+\mathrm{G}-\mathrm{gp}$ when compared to that of FB1-gp ( $p>0.05)$, (Fig. 7).

\subsubsection{Serum Urea level}

The FB1-gp showed a significant increase in the mean serum level of urea by $30 \%(p=0.003)$ when compared to that of C-gp. The G-gp could return back the mean serum level of urea to normal level when compared to that of C-gp that means could significantly decreased the mean serum level of urea by $23 \%$ ( $p=$ 0.002 ) when compared to that of FB1-gp. It could also significantly decreased the mean serum level of urea by $18 \%$ $(p=0.013)$ in comparison with that of Sgp. The S-gp recorded a significant increase in the mean serum level of urea by $22 \%(p=0.015)$ in respect to that of $\mathrm{C}$ gp.The $\mathrm{S}+\mathrm{G}-\mathrm{gp}$ showed no significant difference in the mean serum level of 
urea when compared to that of FB1-gp ( $p>0.05$ ), (Fig. 7).

\subsubsection{Serum Malondialdehyde (MDA) level}

The FB1-gp has been recorded a very significant elevation in the mean level of Malondialdehyde (MDA), this elevation reached $137 \%(p=0.000)$, about three folds higher than that of C-gp. A significant decrease in the mean level of
MDA was observed in S-gp, G-gp and S+G-gp by $47 \%(p=0.000), 42 \%(p=$ $0.000)$ and $29 \%(p=0.000)$ respectively in comparison with that of FB1-gp, while they have been recorded a significant increase in the mean level of MDA by $24 \%(\mathrm{p}=0.006), 35 \%(\mathrm{p}=0.000)$ and $52 \%(\mathrm{p}=0.000)$, respectively in respect to that of C-gp, (Fig. 8).

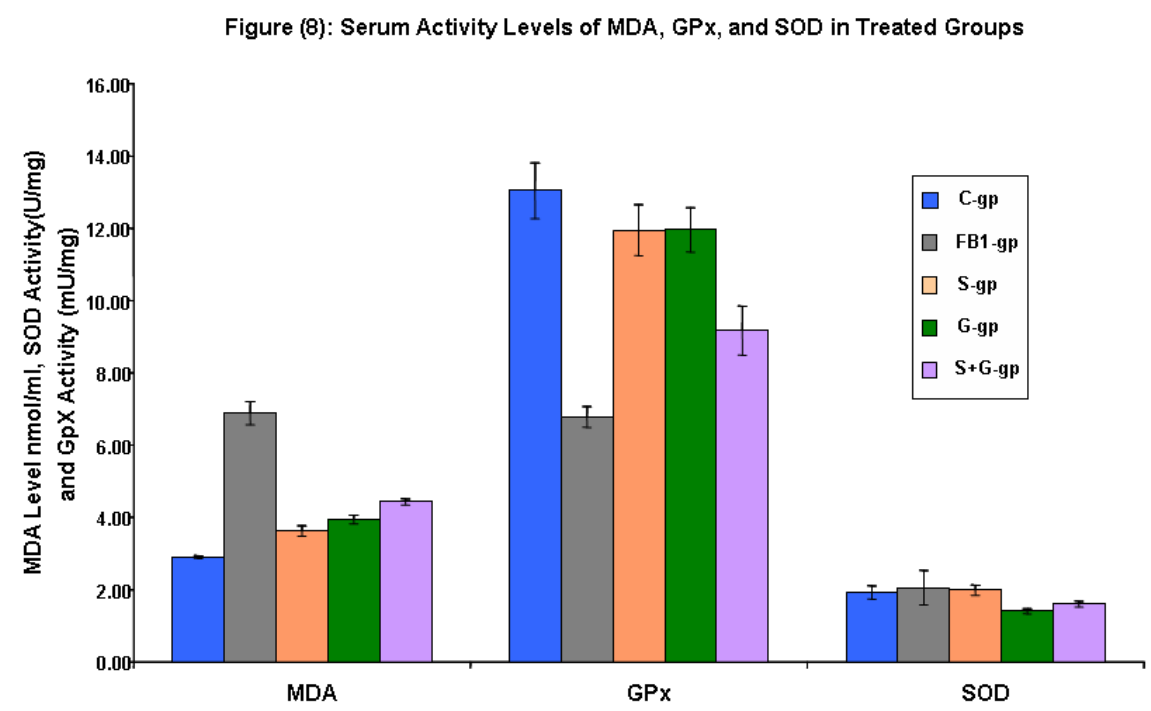

2.1.11.Liver glutathione peroxidase (GPx) level

A significant decrease in the mean activity level of glutathione peroxidase (GPx) in liver by $48 \%(p=0.000)$ has been recorded by FB1-gp when compared to that of C-gp. The treatment of rats with both $\mathrm{S}$ and $\mathrm{G}$ separately after FB1 administration significantly increased the mean serum activity level of GPx by $76 \%(p=0.000)$ in respect to that of FB1-gp. In case of S+G-gp it has been recorded a significant increase in the mean activity level of GPx in liver by $35 \%(p=0.002)$ in respect to that of FB1-gp, but still less than that of C-gp, S-gp and G-gp by $29 \%(p=0.000), 23 \%$ $(p=0.000)$, and $23 \% \quad(p=0.001)$ respectively, (Fig. 8).

2.1.12. Serum level of superoxide dismutase (SOD)

Administration of FB1 showed no significant difference in the mean serum activity level of superoxide dismutase
(SOD) when compared to that of C-gp, ( $p$ $>0.05)$. The treatment of rats with $\mathrm{S}, \mathrm{G}$, and $\mathrm{S}+\mathrm{G}$ after $\mathrm{FB} 1$ administration showed no significant difference in the mean serum activity level of SOD when compared to that of C-gp and FB1-gp, ( $p$ $>0.05)$ as the same among the treated groups when compared to each other, $(p$ $>0.05$ ), (Fig. 8).

\section{Histopathological results}

Microscopic investigations of liver sections (stained with $\mathrm{H} \& \mathrm{E}$ ) showed the normal and histopathological features of the liver of control and all treated groups. Control animals showed the normal liver lobular architecture which is formed of radiating strands of cells (hepatocytes) around a central vein, hepatocytes are polyhedral in shape with relatively large sizes with prominent centrally located nuclei. Between cell strands there are sinusoids which are narrow blood spaces with irregular boundaries composed essentially of a single layer of fenestrated 
endothelial cells (Fig. 25 A). No abnormal changes were seen in any of the livers of the control rats.

In treated groups, feeding of rats with fumonisin B1 contaminated corn $(250 \mathrm{mg} / \mathrm{kg}$ diet) caused toxic injury in livers of all treated animals, FB1 treatment resulted in extensive hepatocellular damage, as evidenced by the presence of portal inflammation, pyknotic cells, congestion of terminal hepatic venules (central veins) and portal vein branches and prominent sinusoidal dilation. FB1 treatment showed an increase in the intensity of the portal inflammatory infiltrate. Moreover, changes of cell size with less cytoplasmic inclusions and appearance of large vacuoles were observed. Signs of necrosis in some hepatic areas were also marked in FB1 treated animals (Fig. 9 B $\& \mathrm{C})$.

On the other hand, the rats fed on GSE, silymarin, and both of them after FB1 administration showed less signs of amelioration. Although mild cloudy cells, pyknotic nuclei, infiltration of lymphocytes, ruptured boundaries of vascular wall and appearance of larger sinusoids are still found; the regeneration of hepatocytes, activation of Kupffer cells, and rearrangement of hepatocytes displaying architecture with less appearance of necrotic areas (Fig. 10).

\section{DISCUSSION}

Fumonisins are a group of mycotoxins that cause different diseases in animals. Biochemically, fumonisin B1 inhibits ceramide synthase (sphinganine and sphingosine-N-acetyltransferase), leading to the accumulation of sphingoid bases, sphingoid base metabolites, and depletion of more complex sphingolipids (Merrill et al., 1996). In addition, fumonisin $\mathrm{B} 1$ produces reactive oxygen species (ROS).

ROS are capable of reacting with proteins, lipids, and nucleic acids leading to lipid peroxidation in biological membranes. This in turn affects enzymatic processes such as ion pump activity and damages the DNA, thereby inhibiting transcription and repair (Chatterjee et al., 2000; 1999). The discovery of new antioxidants has witnessed unprecedented interest in recent years owing to their potential applications in the treatment of ROSinduced diseases.

There have been considerable public and scientific interests in the therapeutic benefits of natural antioxidants, such as polyphenols. Epidemiological studies have shown relationships between the consumption of polyphenol-rich foods and the prevention of diseases such as cancer and coronary heart disease (Adlercreutz \& Mazur, 1997; Steinmetz \& Potter, 1996).

The choice of male rats in the present study was based on previous studies that showed male rats to be more sensitive to the effects of fumonisins than female ones (Voss et al., 1998). In the past, Gelderblom et al. (1991) and Voss et al. (1995) confirmed that the FB1induced hepatotoxic and nephrotoxic effects which were manifested by a significant $(\mathrm{P}<0.05)$ increase in the clinical chemical parameters associated with liver and kidney function.

Liver Function: The data indicated an elevation in the serum ALT activity representing the damage of heptocytes as a result of FB1 toxicity. Orsi et al. (2007, 2009) reported that FB1 increased the ALT activity in rabbits confirming that the liver is one of the main target organs. Thus agreeing with Voss et al. (1993, 1995) and Bondy et al. (1996) who found that ALT activity was significantly increased in the sera of animals fed a FB1 contaminated diet.

On the other hand, the total protein has been elevated in mice due to FB1 toxicity; a study was done by Voss et al. (1995) and confirmed by Bondy et al. (1995) who recorded an elevation in albumin level too. Those studies 
disagreed with Orsi et al. (2007), where they reported that FB1 decreased the total protein and albumin levels in rabbits. The current work does not record any change on both levels of total protein and albumin. That contradiction might be due to the sensitivity differences for each animal study in their work and the current work. Where Orsi et al., (2009) has reported that rabbit is more susceptible to FB1 than other animals that could lead to complete liver damage.

Kidney function: Riley et al. (1994) were the first group who reported that the FB1 disrupted significantly the sphingolipid metabolism in the kidneys of rats receiving FB1 contaminated diet. That result was supported by Gumprecht et al. (1995) and Bucci et al. (1998), who showed nephrotoxic effects due to significant increase in the creatinine, urea and uric acid concentrations. Recently, Orsi et al. (2009) reported an increase in the urea and creatinine concentrations demonstrating that the kidney is the main target organs of FB1, thus confirming our findings where creatinine, urea and uric acid concentrations were significantly elevated.

The Lipid profile: The data indicated an elevation in the Lipid profile including total cholesterol (TC), HDL-C, LDL-C and $\mathrm{TG}$ concentrations, that indicating hepatic injury. This is in agreement with similar findings that obtained by previous works. Voss et al. (1995), Edrington et al. (1995) and Bondy et al. (1996) found that a significant elevation on total cholesterol level has been recorded due to FB1 toxicity. Those findings were confirmed by El-Nekeety et al. (2007). Likewise, TG concentration was significantly increased in the sera of animals fed a diet containing FB1 (Voss et al., 1993; Edrington et al., 1995; ElNekeety et al., 2007). As mentioned before, Bondy et al. (1995) found an elevation in the cholesterol concentration which agrees with our investigations but the same study reported that TG was unaffected by FB1, this disagrees with the current results which indicated an elevation in the TG concentration.

The elevation in serum cholesterol (HDL-C, LDL-C) has been suggested as an early sign of FB-toxicosis, that increase has been reported in broilers (Ledoux et al., 1992), calves (Osweiler et al., 1993), and swine (Colvin et al., 1993). Elevated serum cholesterol and triglycerides are probably associated with biliary obstruction and acute hepatic injury as explained by Edrington et al. (1995). El-Nekeety et al. (2007) attributed the increase in LDL and HDL levels to the need for an increase in lipoprotein to carry the water insoluble cholesterol which is elevated in FBinduced toxicity.

Oxidative stress: Another consequence of FB1 toxicity is oxidative stress. A significant elevation in the concentration of the lipid peroxidation product MDA was recorded in the FB1-gp when compared to that of the control gp that indicates that FB1 stimulates the production of ROS. In the FB1-gp a great reduction in the GPx activity was recorded. These findings were characteristic of the hepatic and renal injury. FB caused enhanced lipid peroxides in rats which resulted in freeradical-mediated toxicity (El-Nekeety et al., 2007). The targets of oxidative damage are usually critical biomolecules such as nucleic acids, protein and lipids (Hoehler, 1998). Stockmann-Juvala et al. (2004) proved that FB evokes oxidative stress, which may contribute at least in part to FB toxicity and carcinogenicity.

Glutathione plays an important role in the detoxification of the reactive and toxic metabolites of mycotoxins. Several studies have reported that liver necrosis begins when the glutathione stores are almost depleted (Mitchell et al., 1973; Abdel-Wahhab and Aly, 2003; 2005). Moreover, the reduced level of GPX may be explained by the association of GPX with FB1 or its metabolites (Abel and 
Gelderblom, 1998; Abdel- Wahhab et al., 2002).

\section{The treatment with silymarin:}

The liver function:

Because the liver performs many vital functions in the human body, liver damage causes unbearable problems (Mitra et al., 1998; Chattopadhyay, 2003). Thus studying hepatoprotective compounds is important. Dietary polyphenols are thought to be beneficial to human health by exerting various biological effects such as free radical scavenging, metal chelation, modulation of enzymatic activity, and alteration of signal transduction pathways (Singh \& Aggarwal, 1995; Stocker, 1999; Yoshioka et al., 1995).

In the treated group (S-gp) silymarin dramatically reduced the elevation of ALT activity and increased the albumin level. Silymarin is frequently used in the treatment of liver diseases where it is capable of protecting liver cells directly. It does this through stabilizing the cell membrane by preventing liver glutathione depletion (Valenzuela et al., 1989) and inhibiting lipid peroxidation (Mira et al., 1994). The stimulatory effect of silymarin on liver regeneration was observed only in damaged livers (Sonnenbichler and Zetl, 1986), indicating that silymarin increases regeneration potency of damaged liver tissues. The pharmacological properties of silymarin involve regulating cell membrane permeability and integrity, inhibiting leukotriene, scavenging reactive oxygen species, suppressing NF$\mathrm{kB}$ activity, depression of protein kinases, and collagen production, silymarin is able to stabilize cellular membrane (Saller et al., 2001).

\section{The kidney function:}

High values of creatinine, urea and uric acid as results of FB1 toxicity indicate kidney damage. In the treated Sgp, milk thistle extract decreased the creatinine and uric acid levels but could not change the urea level. In animal studies, silymarin has shown protective effect against damage to kidney from acetaminophen, cisplatin (platinol), and vincristine (oncovin) partly by reducing lipid peroxidation (Sonnenbichler et al., 1999). It is important that the protective agent is present in renal tissue before damage occurs. Karimi et al. (2005) studied the protective effect of silymarin against cisplatin nephrotoxicity. They supposed that complete protection did not result when silymarin was given after administration of cisplatin. Silymarin mechanism for protection against cisplatin toxicity may be due to the inhibition of lipid peroxidation by scavenging free radicals and increasing intracellular glutathione.

\section{The lipid profile:}

In the treated group (S-gp), silymarin dramatically reduced the elevated levels of TC, LDL and TG when compared to that of FB1-gp. Silymarin, an antioxidant has long been used in the treatment of liver diseases (Naveau, 2001; Laekeman et al., 2003). The antihypercholesterolemic effect of silymarin was associated with liver cholesterol reduction (Krecman et al., 1998), which improves cholesterol uptake from blood (Steinberg et al., 1989).

\section{The oxidative stress:}

In case of treated group (S-gp), silymarin reduced MDA levels and increased the GPx activity as it did in the protective group. Herbal polyphenolic compounds like in milk thistle extract can function as antioxidant and antiprooxidant by scavenging reactive oxygen species via enzymatic and nonenzymatic reactions (Pyo et al., 2004; Marja et al., 1999; Sakihama et al., 2002). Silymarin components inhibit linoleic acid peroxidation catalyzed by lipoxygenase (Fiebrich and Koch, 1979) and also protect rat liver mitochondria and microsomes in vitro against the formation of lipid peroxides induced by various agents (Bindoli et al., 1990). 
Silymarin can also interact directly with cell membrane components to prevent any abnormalities in the content of lipid fraction responsible for maintaining normal fluidity (Muriel and Mourelle, 1990).

\section{The treatment with Grape seed} extract:

The liver function: In the treated group, GSE significantly reduced the elevation of ALT activity, but in contrast to its action in the protected group GSE elevated the albumin and total protein levels suggesting that GSE could partly return the liver to its normal condition. Yousef et al. (2009) reported that animals receiving combined cisplatinGSE treatment showed significant alleviation of the decreased values of proteins compared to cisplatin treated group. Total protein concentration is likely to be decreased if there is inhibition of protein synthesis or if degradation of protein is promoted (Heidenreich et al., 1999). GSE significantly attenuated the hepatotoxicity as an indirect target of cisplatin (Yousef et al., 2009), this effect of GSE pretreatment supports the idea that it is bioavailable and exhibits potent antioxidant and anti-inflammatory effects (Bagchi et al., 2002).

\section{The Kidney function:}

The concentrations of urea and creatinine determine renal function and are thus biomarkers for kidneys disease (Levey et al., 1999). GSE indirectly corrects body homeostasis through its improvement of kidney function. In addition to those studies our lab studied the nephrotoxocity of GSE and reported that GSE has no nephrotoxicity (Abd Elwahab et al., 2008). The current study proved that GSE has nephroprotective effect too, where; GSE could return back the creatinine and urea levels to normal. GSE could not change the uric acid elevated levels in the treated G-gp, it might be effective only when it is administrated before and not after the toxicity.

The Lipid Profile: Oral administration of proanthocyanidins from grape seed produced a hypocholesterolemic effect in a high cholesterol animal feed model; specifically it prevented an increase in total and LDL plasma cholesterol (Fine, 2000, El-Adawi et al., 2006). These findings are confirmed by Yousef et al. (2009) who showed that administration of GSE combined with cisplatin has been reduced the levels of cholesterol when compared to cisplatin group. GSE significantly decreased the levels of TC, HDL-C, LDL-C, and TG in the treated group. El-Adawi et al. (2006) reported that GSE-supplemented diet exhibited an obvious hypolipidemic effect in rats fed on high cholesterol diet. GSE could reduce the TC, LDL and TG in GSE pre and post treated groups. The hypolipidemic effect of GSE may result from increasing the rate of cholesterol catabolism by increasing the activity of hepatic cholesterol 7-a-hydroxylase enzyme. This enzyme is the rate-limiting enzyme of bile acid biosynthesis, thus suggesting that GSE could stimulate the conversion of cholesterol to bile acids, an important pathway of elimination of cholesterol from body (Del Bas et al., 2005). The water-soluble antioxidant, proanthocyanidins in the GSE might trap ROS in aqueous series such as plasma thereby inhibiting oxidation of LDL.

\section{Oxidative stress:}

Increased lipid peroxidation is thought to be a consequence of oxidative stress. This occurs when the dynamic balance between prooxidant and antioxidant mechanism is impaired (Kumari and Menon, 1987). ROS may attack any type of molecules, but their main target appears to be polyunsaturated fatty acids, which is the precursor of lipid peroxide formation (Gutteridge, 1982). ROS are highly toxic byproducts of aerobic metabolism; react unfavorably with surrounding macromolecules 
resulting in severe cell and tissue damage. The antioxidant and free radical scavenging ability of GSE may be to the ability of polyphenols in the extract, especially flavonoids, to modulate the expression of gamma-glutamyl cystein synthetase which catalyses the rate limiting step in the production of endogenous antioxidant in cells, specifically glutathione. Thus, this enzyme plays a crucial role in cellular antioxidant mechanism and xenobiotics' detoxification (Moskaug et al., 2005). Consequently, the protective effects of the gamma-glutamyl cysteine synthetase administered in this study may be due to the elevated GPx activity when compared to that of the FB1-gp.

The current work reveals that the activity of SOD was not affected suggesting that the formation of superoxide is not a prominent feature during FB1-induced hepatotoxicity as was suggested previously (Sahu et al., 1998; Marnewick et al., 2009). GSE significantly reduced the level of MDA and elevated the GPx activity in comparison with FB1-gp. It is proposed that the consumption of flavonoid-rich foods and beverages helps to limit oxidant damage in the body (Van Acker et al., 1996; Yamanaka et al., 1997). In vitro experimental results have demonstrated that proanthocyanidins have specificity for the hydroxylradical (Fine 2000; Zayachkivska et al., 2006). Also, in the treated group (G-gp) GSE significantly decreased the levels of MDA with an elevation of the GPx activity means that GSE post treatment could have the same effect of pretreatment. Tebib et al. (1997) reported that plasma tissue MDAs in rats fed polymer grape seed tannins were reduced, it can be expected that plasma LDL would be less oxidized, strengthens the beneficial effect of decreased LDL-C concentration.

The biochemical function of the selenium containing enzyme glutathione peroxidase is to reduce lipid hydroperoxides to their corresponding alcohols and to reduce free hydrogen peroxide to water (Ran et al., 2007). So, any increase in the GPx activity results in a decrease in lipid peroxide levels, thus improving the lipid profile. This may explain the reduced level of MDA and the near normal levels of TC and LDL-C in the group receiving GSE when compared to that of the FB1-gp. The chemical properties of proanthocyanidins in terms of the availability of the phenolic hydrogens as hydrogen donating radical scavengers and singlet oxygen quenchers predict their antioxidant activity (Bagchi et al., 2000) which has been proven to be significantly more potent antioxidants than vitamins $\mathrm{C}$ and E or beta-carotene (Joshi et al., 2001).

The water extract of grape seeds contains a plethora of constituents. HPLC analysis of the used extract showed gallic acid, catechin, epicatechin, and other constituents. Although some flavonoids have pro-oxidant activity, most are potent antioxidants. Catechins for example are stronger antioxidants than ascorbic acid and tocopherol in aqueous and lipid phase models, respectively (Cao et al., 1997). The catechins,(-)-epigallocatechin 3-o-gallate (Matsuzaki and Hara, 1985; Uchida et al., 1992), and procyanidolic oligomers from grape seeds (Masquelier, 1988; Meunier et al., 1989) are very active antioxidants in aqueous systems. This suggests that in vivo they may act as radical trappers.

Flavonoids have been shown to inhibit lipid peroxidation formation in rat tissues and also inhibit the free radical production in the cells at various stages. In this context Karthikeyan et al. (2007) reported that GSE treatment reduced the levels of heart TBARS in isoproterenolinduced lipid peroxidation. This indicates that the flavonoids constituents of GSE are responsible for both its antioxidant property and its ability to improve lipid profile. 
Halliwell (2007) concluded that dietary polyphenols were typical xenobiotics, metabolized as such and rapidly removed from the circulation. They may be beneficial in the gut in the correct amounts, but too much may not be good. It was for the first time using mixture of milk thistle and grape seed extracts in the recovery of FB1 toxicity. Both extracts showed a great amelioration in the liver status that was evident from the histopathological results which confirm the biochemical results. In the treated group (S+G-gp), although both extracts could reduce the activity levels of ALT, they significantly reduced the albumin level and did not change the total protein in comparison to that of FB1-gp, suggesting that both extracts could not return back the injured hepatocytes to some extent. We suggest that in case of treated group, the presence of the same concentration of both extracts represents an overload of polyphenol on the treated rats which could not give the promising results as we hope. That suggestion was supported with the statement of Rucinska et al. (2007). Although polyphenols have beneficial antioxidant, anti-inflammatory and anticancer effects, but at higher doses or under certain conditions these compounds may exert toxic prooxidant activities.

Both extracts also reduced the levels of TC, HDL-C, LDL-C, and TG. Thus, both extracts administration before or after FB1 toxicity could partly account for the recovery of toxicity in rats.

Regarding the kidney function, when $\mathrm{S}+\mathrm{G}$ administrated after induction of FB1 toxicity, a significant reduction in the level of creatinine only was recorded, but the levels of urea or uric acid remained at high levels, suggesting that both extracts could not return the damaged kidneys to their normal condition. Those results confirm again the fact that protection is better than treatment (El-Adawi et al., 2011), where the male rats might need longer time to recover and overcome the complications due to toxicity.

\section{REFERENCES}

Allain, C.C.; Poon, L.S.; Chan, C.S.C.; and $\mathrm{Fu}$, P.C. (1974): Enzymatic determination of total serum cholesterol. Clin. Chem., 20: 470475.

Barham, D. and Trinder, P. (1972): An improved colour reagent for the determination of blood glucose by the oxidase system. Analyst, 97:142-5.

Dannis, M. (1951): Determination of phenols by the aminoantipyrine method. Sewage and Ind. Wastes 23, 1516.

Desai, K.; Sullards, C.; Allegood, J.; Wang, E.; Schmelz, E.M; Hartl, M.; Humpf, H.U; Liotta; D.C. Peng, Q. and Merrill, A.H. (2002): Fumonisins and fumonisin analogs as inhibitors of ceramide synthase and inducers of apoptosis, Biochimica et Biophysica Acta, 1585, 188- 92.

Doumas, B.T.; Waston, W.A. and Biggs, H.G. (1971): Albumin standards and the measurement of serum albumin with bromocresol green. Clin. Chim. Acta., 31: 87-96.

Ettinger, M.B.; Ruchhoft, C.C. and Lishka, R.J. (1951): Sensitive 4aminoantipyrine method for phenolic compounds. Anal. Chem. 23: 1783.

Fawcett, J.K. and Scott, J.E. (1960): A rapid and precise method for the determination of urea. J. Clin. Path., 13: 156-159.

Friedwald, W. T.; Levy, R. I. and Fredrickson, D. S. (1972): Estimation of the concentration of low-density lipoprotein cholesterol in plasma, without use of the preparative ultracentrifuge. Clin. Chem. 18:499502.

Gelderblom, W. C.; Kriek, N. P.; Marasas, W. F. and Thiel, P. G. (1991): Toxicity and carcinogenicity of the Fusarium moniliforme 
metabolite, fumonisin $\mathrm{B} 1$, in rats. Carcinogenesis 12:1247-1251.

Gornall, A.G.; Bardawill, C.J. and David, M.M. (1949): Determination of serum proteins by means of the biuret reaction. J. Biol. Chem., 177: 751759.

Gruenwald, J. (2004): PDR for Herbal Medicines 3 rd ed. Montvale, NJ:Thomson PDR.

Haschek, W.M.; Gumprecht, L.A.; Smith, G.W.; Tumbleson, M.E. and Constable, P.D. (2001): Fumonisin toxicosis in swine: An overview of porcine pulmonary edema and current perspectives. Environ Health Perspect, 109: 251-257.

Larsen, K. (1972): Creatinine assay by a reaction-Kinetic principle. Clin. Chim. Acta., 41: 209-217.

Lopez-Virella, M.F.; Stone, P.; Ellis, S. and Colwel, J.A. (1977): Cholesterol determination in high-density lipoproteins separated by three different methods. Clin. Chem., 23: 882-884.

Marasas, W.F.O. (2001): Discovery and occurrence of the fumonisins: a historical perspective. Environ. Health Perspect. 109: 239-243.

Marasas, W.F.O. (1996): Fumonisins: History, world-wide occurrence and impact. In: Jackson, L., De Vries, J.W., Bullerman, L.B. (Eds.), Fumonisins in Food. Plenum Press, New York, pp. 1-17.

Marnewick, J.L.; van der Westhuizen, F.H.; Joubert, E.; Swanevelder, S.; Swart, P. and Gelderblom, W.C.A. (2009): Chemoprotective properties of rooibos (Aspalathus linearis), honeybush (Cyclopia intermedia) herbal and green and black (Camellia sinensis) teas against cancer promotion induced by fumonisin B1 in rat liver. Food Chem. Toxicol. 47: 220-229.

Ohkawa, H.; Ohishi, N. and Yagi, K. (1979): Assay for lipid peroxide in animal tissues by thiobarbituric acid reaction. Anal. Biochem., 95: 351358.

Osawa, T. and Namiki, M. (1981): A novel type of antioxidant isolated from leaf wax of Eucalyptus leaves. Journal of Agricultural and Biological Chemistry, 45: 735-739.

Oser, B. (1965): Preparation of serum. In: Hawk's physiological chemistry. Oser, B. (ed.). TATA Mc Graw-Hill publishing Co., New Delhi. 357-358.

Paglia, D.E. and Valentine, W.N. (1967): Studies on the quantitative and qualitative characteristics of erythrocyte glutathione peroxidase, Journal of Laboratory and Clinical Medicine. 158-169.

Reitman, S. and Frankel, S. (1957): A Colorimetric method for the glutamic-pyruvate transaminase. Am. J. Clin. Path. 28: 56-63.

Rheeder, J. P.; Marasas, W. F. O.; Thiel, P. G. and Sydenham, E. W. (1992): Fusarium moniliforme and fumonisins in corn in relation to human oesophageal cancer in Transkei. Phytopathology 82: 353357.

Schulz, V.; Hansel, R.; Tyler, V. and Blumenthal, M. (2004): Rational Phytotherapy 5 th ed. Berlin: Springer-Verlag

Schuppan, D.; Jia, J-D. and Brinkhaus B. (1999): Herbal products for liver diseases: a therapeutic challenge for the new millennium. Hepatology. 30: 1099-104

Shephard, G.S.; Thiel, P.G.; Stockenstrom, S. and Sydenham, E.W. (1996a): Worldwide survey of fumonisin contamination of corn and corn-based products, J. AOAC Int., 79, 671-87.

Shephard, G.S.; van der Westhuizen, L.; Thiel, P.G.; Gelderblom, W.C.A.; Marasas, W.F.O. and van Schalkwyk, D.J. (1996b): Disruption of sphingolipid metabolism in nonhuman primates consuming diets of fumonisin-containing Fusarium 
moniliforme culture material, Toxicon., 34: 527-34.

Sonnenbichler, J.; Goldberg, M.; Hane, L.; Madubunyi, I.; Vogl, S. and Zetl,

I. (1986): Stimulatory effect of Silibinin on the DNA synthesis in partially hepatectomized rat livers: non-response in hepatoma and other malign cell lines. Biochem Pharmacol 35:538-541.

Voss, K. A.; Chamberlain, W. J.; Bacon, C. W.; Herbert, R. A.; Walters, D. B. and Norred, W. P. (1995): Subchronic feeding study of the mycotoxin fumonisin $\mathrm{B} 1$ in $\mathrm{B} 6 \mathrm{C} 3 \mathrm{~F} 1$ mice and Fischer 344 rats. Fundam Appl. Toxicol. 24:102-110.

Wichtl, M. (2004): Herbal Drugs and Phytopharmaceuticals 3 rd ed. Boca Ratón, FL: CRC Press.

Bown, D. (2001): The Herb Society of America, New Encyclopedia of Herbs and Their Uses. Dorling Kindersley Ltd., London, p. 407.

Celik, H.; Agaoglu, Y. S.; Fidan, Y.; Marasali, B. and Soylemezoglu, C. (1998): General Viniculture. Sun Fidan A.S. Professional Books Series No. 1, 1-253, Ankara

Palma, M.; Taylor, L. T.; Varela, R. M.; Cutler, S. J. and Cutler, H. G. (1999): Fractional extraction of compounds from grape seeds by supercritical fluid extraction and analysis for antimicrobial and agrochemical activities. J. Agric. Food Chem., 47: 5044-5048

Merrill, A. H.; Liotta, D. C. and Riley, R. T. (1996): Fumonisins: fungal toxins that shed light on sphingolipid function. Trends Cell Biol., 6: 218223.

Chatterjee, P. K.; Cuzzocrea, S.; Brown, P. A.; Zacharowski, K.; Stewart, K. N.; Mota-Filipe, H. and Thiemermann, C. (2000): Tempol, a membrane-permeable radical scavenger, reduces oxidant stressmediated renal dysfunction and injury in the rat. Kidney Int., 58: 658-673.
Adlercreutz, H. and Mazur, W. (1997): Phyto-oestrogens and Western diseases. Ann. Med., 29: 95-120.

Voss, K. A.; Riley, R. T.; Bacon, C. W.; Meredith, F. I. and Norred, W. P. (1998): Toxicity and sphinganine levels are correlated in rats fed fumonisin B1 (FB1) or hydrolyzed FB1. Environ. Toxicol. Pharmacol., 5: 101-104.

Orsi, R. B.; Dilkin, P.; Xavier, J. G.; Aquino, S.; Rocha, L. O. and Correa, B. (2009): Acute toxicity of a single gavage dose of fumonisin B1 in rabbits. Chem. Biol. Interact., 179: 351-355.

Orsi, R. B.; Oliveira, C. A.; Dilkin, P.; Xavier, J. G.; Direito, G. M. and Correa, B. (2007): Effects of oral administration of aflatoxin B1 and fumonisin B1 in rabbits (Oryctolagus cuniculus). Chem. Biol. Interact., 170: 201-8.

Bondy, G.; Barker, M.; Mueller, R.; Fernie, S.; Miller, J. D.; Armstrong, C.; Hierlihy, S. L.; Rowsell, P. and Suzuki, C. (1996): Fumonisin B1 toxicity in male Sprague-Dawley rats. Adv Exp. Med. Biol., 392: 251-264.

Bondy, G.; Suzuki, C.; Barker, M.; Armstrong, C.; Fernie, S.; Hierlihy, L.; Rowsell, P. and Mueller, R. (1995): Toxicity of fumonisin B1 administered intraperitoneally to male Sprague-Dawley rats. Food Chem. Toxicol., 33: 653-665.

Gumprecht, L. A.; Marcucci, A.; Weigel, R. M.; Vesonder, R. F., Riley, R. T.; Showker, J. L.; Beasley, V. R. and Haschek, W. M. (1995): Effects of intravenous fumonisin B1 in rabbits: nephrotoxicity and sphingolipid alterations. Nat. Toxins, 3: 395-403.

Voss, K. A.; Chamberlain, W. J.; Bacon, C. W. and Norred, W. P. (1993): A preliminary investigation on renal and hepatic toxicity in rats fed purified fumonisin B1. Nat. Toxins, 1: 222-228. 
El-Nekeety, A. A.; El-Kholy, W.; Abbas, N. F.; Ebaid, A.; Amraa, H. A. and Abdel-Wahhab, M. A. (2007): Efficacy of royal jelly against the oxidative stress of fumonisin in rats. Toxicon, 50: 256-269.

Ledoux, D. R.; Brown, T. P.; Weibking, T. S. and Rottinghaus, G. E. (1992): Fumonisin toxicity in broiler chicks. J. Vet. Diagn. Invest., 4: 330-333.

Colvin, B. M.; Cooley, A. J. and Beaver, R. W. (1993): Fumonisin toxicosis in swine: clinical and pathologic findings. J. Vet. Diagn. Invest., 5: 232-241.

Edrington, T. S.; Kamps-Holtzapple, C. A.; Harvey, R. B.; Kubena, L. F.; Elissalde, M. H. and Rottinghaus, G. E. (1995): Acute hepatic and renal toxicity in lambs dosed with fumonisincontaining culture materials. J. Anim. Sci., 73: 508-515.

Hoehler, D. (1998): Ochratoxin A in food and feed: occurrence, legislation and mode of action. Ernahrungswiss, 37: 2-12.

El-Adawi, H.; El-Azhary, D.; Abd ElWahab, A.; El-Shafeey, M. and Abdel-Mohsen, M. (2011): Protective effect of milk thistle and grape seed extracts on fumonisin B1 induced hepato- and nephro-toxicity in rats. J. Med. Plants Res., 5(27): 6316-6327.

Rucinska, A.; Kirko, S. and Gabryelak, T. (2007): Effect of the phytoestrogen, genistein-8-Cglucoside, on Chinese hamster ovary cells in vitro. Cell Biol. Int., (in press).

Halliwell, B. (2007): Dietary polyphenols: Good, bad, or indifferent for your health? Cardiovascular Research, 73: 341347

Stockmann-Juvala, H.; Mikkola, J.; Naarala, J.; Loikkanen, J.; Elovaara, E. and Savolainen, K. (2004): Fumonisin B1-induced toxicity and oxidative damage in U-118MG glioblastoma cells. Toxicol., 202: 173-183.

Abdel-Wahhab, M. A. and Aly, S. E. (2005): Antioxidant property of Nagilia Sativa (Black cumin) and Syzygium Aromaticum (Clove) Rats during Aflatoxicosis. Appl. Toxicol., 25: 218-223.

Abdel-Wahhab, M. A.; Amer, H. A.; Hassan, N. S.; Hassan, A. M. and Naguib, Kh. M. (2002): Effects of garlic and cabbage extracts on fuminisin-induced toxicity in rats. Egypt. Soc. Toxicol., 26: 1-12.

Chattopadhyay, R. R. (2003): Possible mechanism of hepatoprotective activity of Azadirachta indica leaf extract. Ethnopharmacol., 89: 217219.

Yoshioka, K.; Deng, T.; Cavigelli, M. and Karin, M. (1995): Antitumor promotion by phenolic antioxidants: inhibition of AP-1 activity through induction of Fra expression. Proc. Natl. Acad. Sci., U S A 92: 49724976.

Valenzuela, A.; Aspillaga, M.; Vial, S. and Guerra, R. (1989): Selectivity of silymarin on the increase of the glutathione content in different tissues of the rat. Planta Med., 55: 420-422.

Mira, L.; Silva, M. and Manso, C. F. (1994): Scavenging of reactive oxygen species by silibinin dihemisuccinate. Biochem. Pharmacol., 48: 753-759.

Saller, R.; Meier, R. and Brignoli, R. (2001): The use of silymarin in the treatment of liver diseases. Drugs, 61: 2035-2063.

Sonnenbichler, J.; Scalera, F.; Sonnenbichler, I. and Weyhenmeyer, R. (1999): Stimulatory effects of silibinin and silicristin from the milk thistle Silybum marianum on kidney cells. Pharmacol. Exp. Ther., 290: 1375-1383.

Karimi, G.; Ramezani, M. and Tahoonian, Z. (2005): Cisplatin 
nephrotoxicity and protection by milk thistle extract in rats. Evid. Based Complement Alternat. Med., 2: 383386

Laekeman, G.; De Coster, S. and De Meyer, K. (2003): [St. Mary's Thistle: an overview]. J. Pharm. Belg., 58: 28-31.

Krecman, V.; Skottova, N.; Walterova, D.; Ulrichova, J. and Simanek, V. (1998): Silymarin inhibits the development of diet-induced hypercholesterolemia in rats. Planta Med., 64: 138-142.

Steinberg, D.; Pathasarathy, S.; Carew, T. E.; Khoo, J. C. and Witztum, J. L. (1989): Modifications of low-density lipoprotein that increase atherogenicity. N. Engl. J. Med., 320: 915-924.

Sakihama, Y.; Cohen, M. F.; Grace, S. C. and Yamasaki, H. (2002): Plant phenolic antioxidant and prooxidant activities: phenolics-induced oxidative damage mediated by metals in plants. Toxicol., 177: 67-80.

Fiebrich, F. and Koch, H. (1979): Silymarin, an inhibitor of lipoxygenase. Experientia, 35:15481560.

Bindoli, A.; Cavallini, L. and Siliprandi, N. (1990): Inhibitory action of silymarin of lipid peroxide formation in rat liver: effect of silymarin. $\mathrm{J}$ Appl. Toxicol., 10: 281-4

Muriel, P. and Mourelle, M. (1990): Prevention by silymarin of membrane alterations in acute CCl4 liver damage. J. Appl. Toxicol., 10: 275279.

Yousef, M. I.; Saad, A. A. and ElShennawy, L. K. (2009): Protective effect of grape seed proanthocyanidin extract against oxidative stress induced by cisplatin in rats. Food and Chemical Toxicology, 47(6):11761183.

Heidenreich, O.; Neininger, A.; Schratt, G.; Zinck, R.; Cahill, M.A. and Engel, K. (1999): MAPKAP kinase 2 phosphorylates serum response factor in vitro and in vivo. Biol. Chem., 274: 14434-14443.

Bagchi, D.; Bagchi, M.; Stohs, S. J.; Ray, S. D.; Sen, C. K. and Preuss, H. G. (2002): Cellular protection with proanthocyanidins derived from grape seeds. Ann. N.Y. Acad. Sci., 957: 260-270.

Levey, A. S.; Bosch, J. P.; Lewis, J. B.; Green, T.; Rogers, N. and Roth, D. (1999): A more accurate method to estimate glomerular filtration rate from serum creatinine: a new prediction equation. Modification of diet in renal disease study group. Ann. Int. Med., 130:460-471.

Abd El-Wahab, A.; El-Adawi, H. and kassem, H. S. (2008): Towards understanding the hepatoprotective effect of grape seeds extract on cholesterol-fed rats. Aust. J. of Basic and Applied Sciences, 2: 412-417.

Fine, A. M. (2000): Oligomeric proanthocyanidin complexes: history, structure, and phytopharmaceutical applications. Alter. Med. Rev., 5: 144-151.

El-Adawi, H.; Abdel Mohsen, M.; Youssef, D. and El-Sewedy, S. (2006): Study on the Effect of Grape Seed Extract on Hypercholesterolemia: Prevention and Treatment. Int. J. Pharm., 2: 593600.

Gutteridge, J. M. C. (1982): Free radicals damage to lipids, amino acids, carbohydrates and nucleic acids, determined by TBA reactivity. Int. J. Biochem., 14: 649-654.

Del Bas, J. M.; Fernandez-Larrea, J.; Blay, M.; Ardevol, A.; Salvado, M. J.; Arola, L. and Blade, C. (2005): Grape seed procyanidins improve atherosclerotic risk index and induce liver CYP7A1 and SHP expression in healthy rats. FASEB, 19: 479-481.

Moskaug, J.; Carlsen, H.; Myhrstad, M. C. W. and Blomhoff, R. (2005): Polyphenols and glutathione 
synthesis regulation. Am. J. Clin. Nutr., 81: 277-283.

Yamanaka, N.; Oda, O. and Nagao, S. (1997): Green tea catechins such as ()-epicatechin and (-)-epigallocatechin accelerate $\mathrm{Cu} 2+$-induced low density lipoprotein oxidation in propagation phase. FEBS Lett., 401: 230-234.

Zayachkivska, O. S.; Gzhegotsky, M. R.; Terletska, O. I.; Lutsyk, D. A.; Yasschenko, A. M. and Dzhura, O. R. (2006): Influence of Viburnum opulus proanthocyanidins on stressinduced gastrointestinal mucosal damage. J. Physiol. Pharmacol., 57: 155-167.

Tebib, K.; Rouanet, J. M. and Besancon, P. (1997): Antioxidant effects of dietary polymeric grape seed tannins in tissues of rats fed a high cholesterol-vitamin E-deficient diet. Food Chemistry., 59: 135-141.

Ran, Q.; Liang, H.; Ikeno, Y.; Qi, W.; Prolla, T. A.; Roberts, L. J.; Wolf, N.; Van Remmen, H. and Richardson, A. (2007): Reduction in glutathione peroxidase 4 increases life span through increased sensitivity to apoptosis. J Gerontol A Biol. Sci. Med. Sci., 62: 932-42.

Bagchi, D.; Bagchi, M.; Stohs, S. J.; Das, D. K.; Ray, S. D.; Kuszynski, C. A.; Joshi, S. S. and Pruess, H. G. (2000): Free radicals and grape seed proanthocyanidin extract: importance in human health and disease prevention. Toxicology, 148: 187197.

Joshi, S. S.; Kuszynski, C. A. and Bagchi, D. (2001): The cellular and molecular basis of health benefits of grape seed proanthocyanidin extract. Curr. Pharm. Biotechnol., 2: 187-200.

Meunier, M. T.; Duroux, E. and Bastide, P. (1989): Activite antiradicalaire d'oligomeres et d'anthocyanosides vis-à-vis de l'anion superoxide et visa-vis de la lipoperoxydation. Plant. Med. Phytother., 23: 267-274.
Karthikeyan, K.; Sarala Bai, B. R. and Niranjali Devaraj, S. (2007): Cardioprotective effect of grape seed proanthocyanidins on isoproterenolinduced myocardial injury in rats. Int. J. Cardiol. 115: 326-333.

Uchida, S.; Ozaki, M.; Suzuki, K. and Shikita, M. (1992): Radioprotective effects of (-)-epigallocatechin 3-Ogallate (green-tea tannin) in mice. Life Sci., 50: 147-152.

Cao, G.; Sofic, E. and Prior, R. L. (1997): Antioxidant and prooxidant behavior of flavonoids: structureactivity relationships. Free Radic. Biol. Med., 22: 749-760.

Riley, R. T.; Hinton, D. M.; Chamberlain, W. J.; Bacon, C. W.; Wang, E.; Merrill, A. H. and Voss, K. A. (1994): Dietary fumonisin B1 induces disruption of sphingolipid metabolism in Sprague-Dawley rats: a new mechanism of nephrotoxicity. J. Nutr., 124: 594-603.

Bucci, T. J.; Howard, P. C.; Tolleson, W. H.; Laborde, J. B.; and Hansen, D. K. (1998): Renal effects of fumonisin mycotoxins in animals. Toxicol Pathol 26:160- 164.

Osweiler, G. D.; Kehrli, M. E.; Stabel, J. R.; Thurston, J. R.; Ross, P. F. and Wilson, T. M. (1993): Effects of fumonisin-contaminated corn screenings on growth and health of feeder calves. Anim. Sci. 71:459-466.

Abdel-Wahhab, M.A. and Aly, S.E. (2003): Antioxidants and radical scavenging properties of vegetable extracts in rats fed aflatoxincontaminated diet. Agric. Food Chem. 51:2409-2414.

Kumari, S.S. and Menon, V.P. (1987): Changes in concentrations of lipid peroxides and activities of superoxide dismutase and catalase in isoproterenol induced myocardial infarction in rats. Indian J. Exp. Biol. 25: 419-423. 

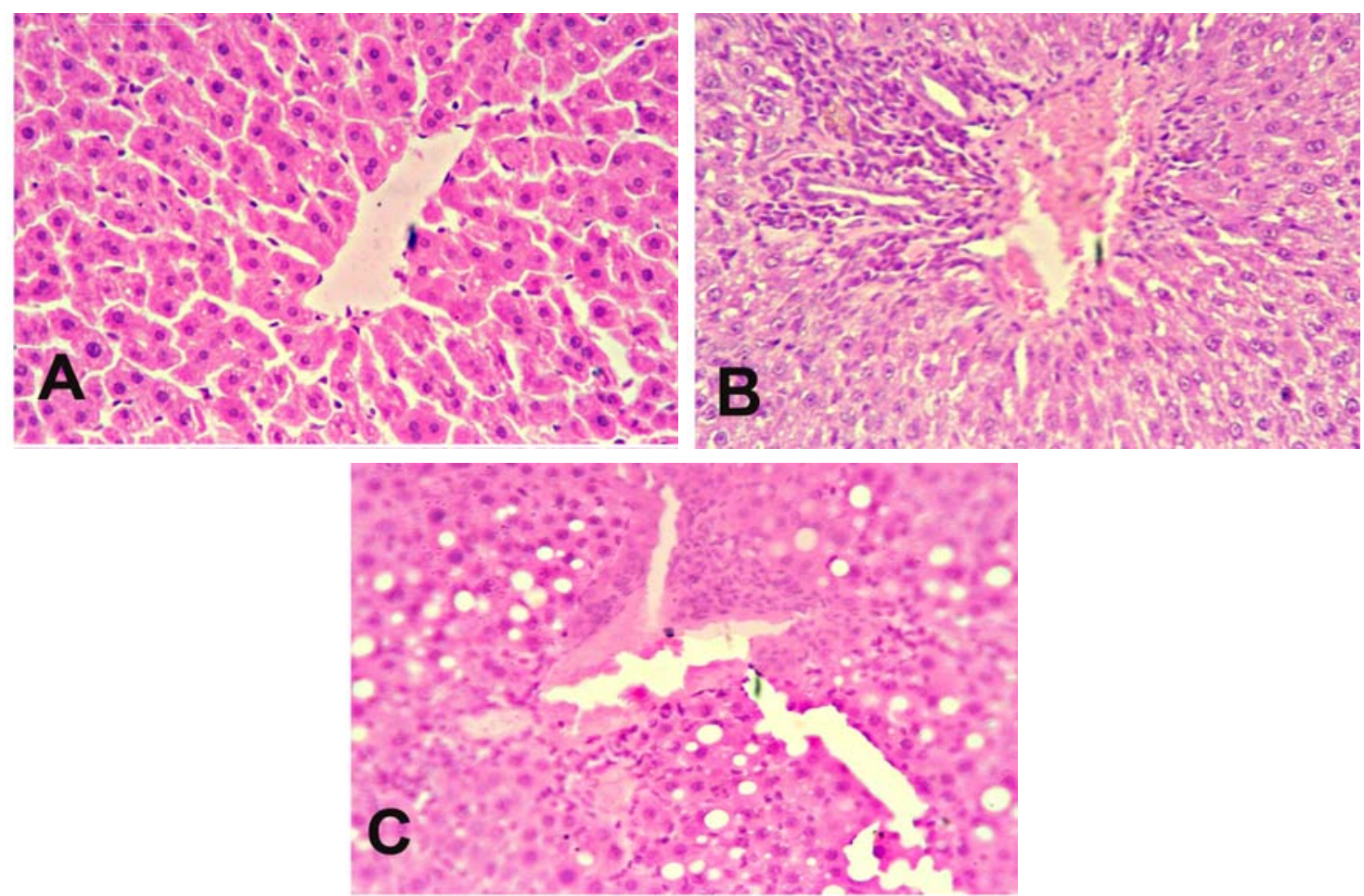

Fig. 9: Section of liver of (A) a control rat, fed on uncontaminated corn, showing normal architecture of hepatocytes, (B) a rat fed on FB1 contaminated corn showing increase of lymphocyte infiltration in portal area (blue arrow), apoptotic bodies (small arrow), pyknotic nuclei and vascular congestion, and (C) a rat in the same FB1-gp showing lymphocyte infiltration, moderate and large sized vacuoles (arrows) and lysis of some hepatocytes (H \& E stain, X 400).
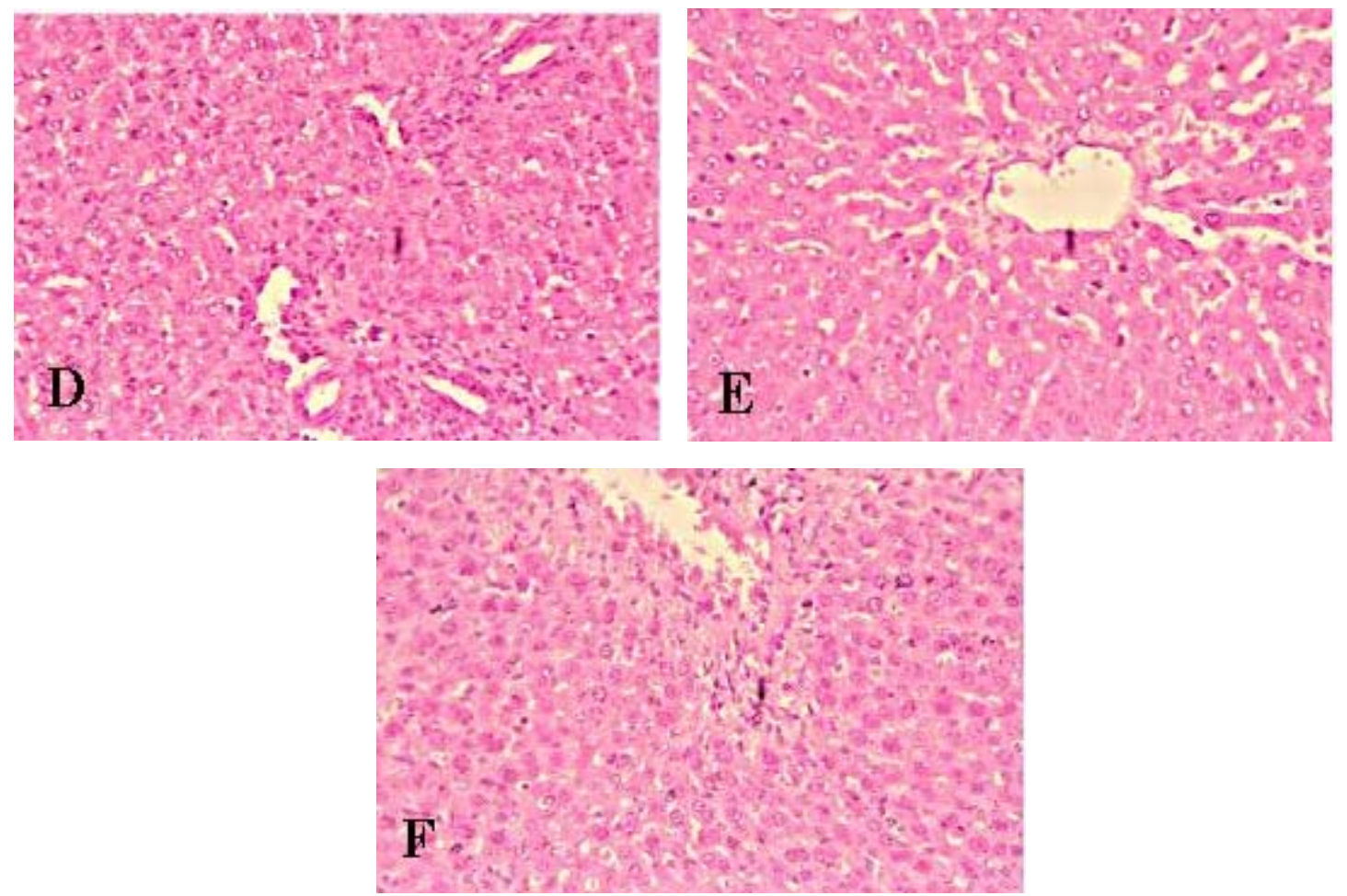

Fig. 10: Section of liver of (D) a rat fed on GSE after FB1 administration, showing cloudy cells, pyknotic nuclei and infiltration of lymphocytes, (E) a rat fed on silymarin after FB1 administration showing regeneration of hepatocytes, activation of Kupffer cells, appearance of pyknotic cells and larger sinusoids, and (F) a rat fed on both $\mathrm{S}+\mathrm{G}$ after $\mathrm{FB} 1$ administration, showing rearrangement of hepatocytes, decrease of pyknotic cells, and appearance of degenerative cells within and surrounding vascular wall (H \& E stain, X 400). 


\title{
ARABIC SUMMARY
}

التأثير المتآزر لمستخلصات كل من نبات شوك الجمل ويذر العنب على امكانية الثفاء من سمية الفيومينيزين

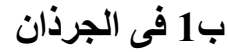

\author{
محمد الثافعى أحمد1"، هالة إبراهيم العدوى1، ضياء الدين بشر الأزهرى، عبير عبدالوهاب1، محمد أحمد

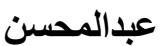 \\ قسم التكنولوجيا الحيوية الطبية، معهد الهندسة الور اثية، مدينة الأبحاث العلمية و التطبيقات التكنولوجية، برج

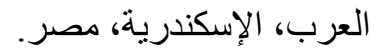

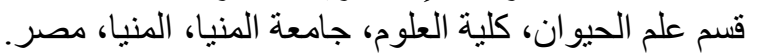

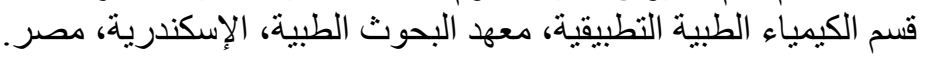

(E.mail: mohamedshafeey@gmail.com)

يعتبر الفيومينيزين ب1 منتج ايض ثانوى ينتج من جنس فطر الفيوزاريوم الذى ينمو على الذرة فى منى

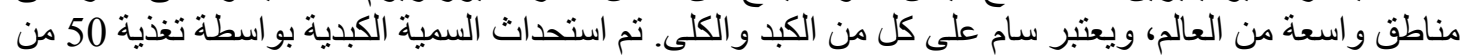

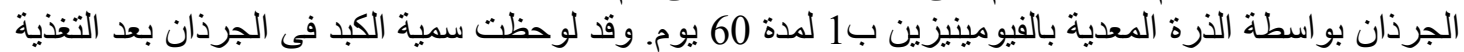

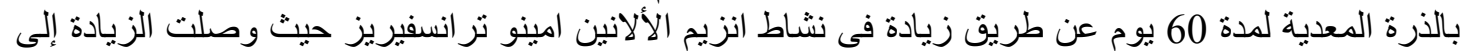

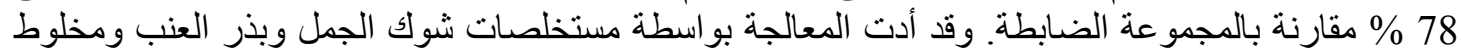

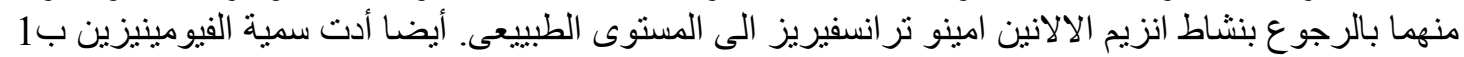

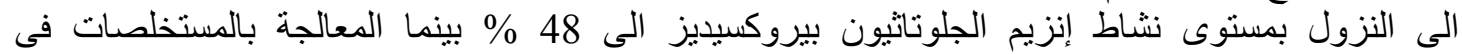

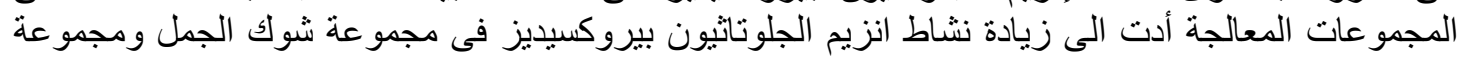

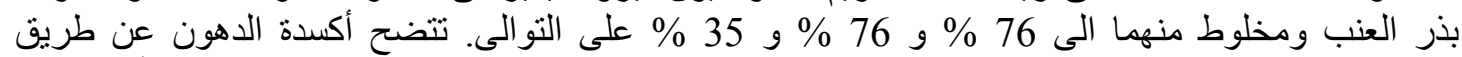

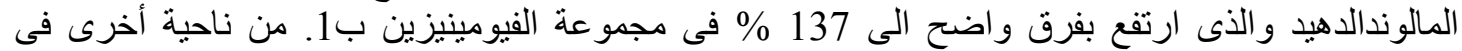

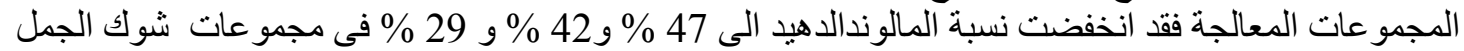

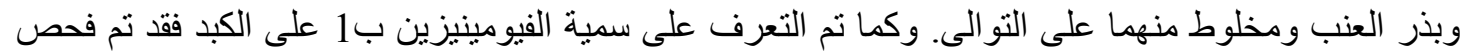

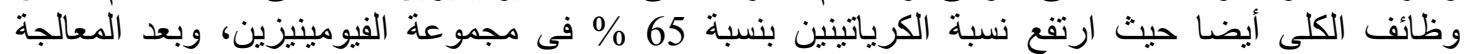

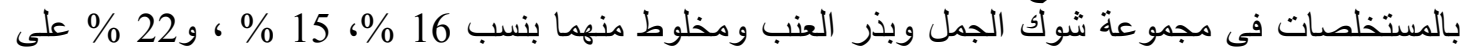

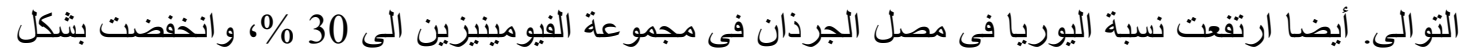

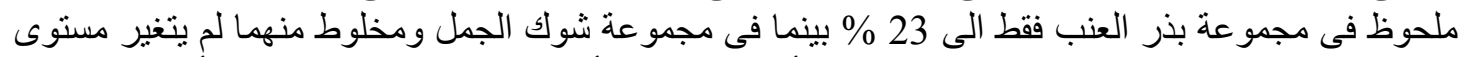

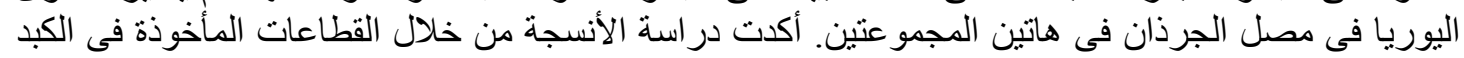

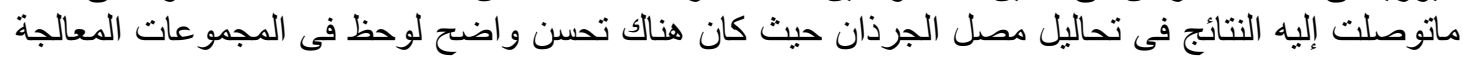

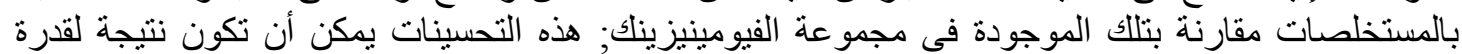

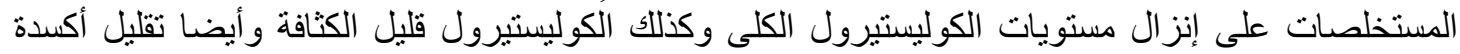
الدهون عن طريق تحسين نشاط الإنزيمات المضادة للأكسدة. 